\title{
Modulation of airway inflammation to prevent exacerbations of COPD
}

\author{
M. Solèr
}

\begin{abstract}
Exacerbations of chronic obstructive pulmonary disease (COPD) are periods in the chronic course of this disease with symptoms of intensified inflammation, induced in part by infections but also by noninfectious irritating mechanisms. Although these exacerbations seem to be linked to accelerated long-term disease progression and impaired quality of life, there are only limited preventive measures available, apart from smoking cessation.

This article compares the effectiveness of different pharmacological treatments for the prevention of COPD exacerbations, including the oral bacterial lysate OM-85.

Given the differences in the mechanism of action of the treatments discussed, this opens some hope for additive or potentiating effects with combined treatments, which will have to be studied in future controlled trials.
\end{abstract}

KEYWORDS: Chronic obstructive pulmonary disease, exacerbation, OM-85, pharmacotherapy, prevention

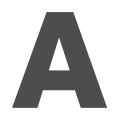
cute exacerbations of chronic obstructive pulmonary disease (AECOPD) are sustained periods with acute onset of symptomatic and functional deterioration of the chronic airways obstruction with worsened cough, breathlessness and changes in sputum volume and colour [1]. Such exacerbations lead to increased utilisation of healthcare resources that include, at least in severe cases, hospitalisations and intensive care. Apart from the economic aspects, exacerbations seem to accelerate the chronic course of functional impairment in COPD. They are related to an accelerated longterm loss in forced expiratory volume in one second (FEV1) $[2,3]$, to reduced physical work capacity and quality of life [4]. For this reason, prevention of exacerbations in COPD has become a topic of major interest in clinical research in COPD in recent years.

The descriptive clinical definition of what constitutes an exacerbation is a consequence of the lack of clear mechanistic insight into the pathogenesis of these bronchitic flare-ups.

There is little controversy about acute inflammation being the hallmark of an exacerbation. These inflammatory changes involve the large bronchi as well as the peripheral bronchioli and some parts of the alveoli during such periods. Initiating events for such inflammatory responses, on top of the chronic inflammatory process characteristic for COPD, are inhalative infections (viruses and bacteria) but also noninfectious, purely irritative stimuli (pollutants) $[1,5,6]$. The cause of a given exacerbation is difficult to define; however, most studies on infectious agents in AECOPD report $\sim 30 \%$ of exacerbations with no identifiable infectious cause. But even in AECOPD with infectious agents demonstrated in sputum or nasopharyngeal secretions, the specific role for this or these viruses or bacteria in the exacerbation event remain speculative, as they may be innocent bystanders, long-term colonisers or even secondary opportunists in the exacerbation originally initiated by a different mechanism.

Epidemiological studies in COPD have demonstrated that the frequency of exacerbations may be an individual characteristic pattern, to some degree independent of the COPD disease stage and lung function [3]. There seem to be patients with more frequent exacerbations even at milder disease stages, who maintain that pattern over prolonged periods of time. However, in general the frequency and the consequences of exacerbations in terms of use of healthcare resources are clearly related to the disease stage as defined by FEV1 [7].

The development of therapeutic approaches to reduce the number and severity of exacerbations is, therefore, an important goal in the long-term treatment strategy for COPD. This approach has the potential to improve quality of life, preserve lung function and possibly prolong survival in addition to being potentially cost saving.
CORRESPONDENCE

$M$. Solèr

St. Claraspital

CH-4016 Basel

Switzerland

Fax: 41616858469

E-mail: markus.soler@claraspital.ch 


\section{PHARMACOLOGICAL PREVENTIVE STRATEGIES}

In recent years, several large-scale clinical trials in COPD have analysed the exacerbation-preventing aspects of different treatments. These include inhaled bronchodilators, inhaled corticosteroids and a limited number of antimicrobial strategies. Most antimicrobial strategies have been used therapeutically in the form of antibiotic treatment during an established exacerbation, apart from vaccinations against influenza and pneumococci, which can protect from these infections which are particularly dangerous for COPD-patients.

\section{LONG-ACTING BRONCHODILATORS}

The use of short-acting $\beta_{2}$-agonists p.r.n. is generally accepted as standard treatment in COPD [1] and has become the usual pharmacological treatment in the placebo-control arm of randomised controlled trials. Compared to this regimen, several long-acting bronchodilators have been tested in longterm trials of $>28$ weeks also under the aspect of prevention of exacerbations. These agents include long-acting $\beta_{2}$-agonists (LABA; formoterol $[8,9]$ and salmeterol $[10,11])$ as well as long-acting anticholinergics (tiotropium) [11-13]. The results of the LABA trials are summarised in table 1. Salmeterol in these studies is the only long-acting $\beta$-agonist with a significant effect on the rate of exacerbations, while formoterol, in two daily doses, failed to show such an effect in two trials with a slightly smaller sample size. The trials with tiotropium are listed in table 2. These studies of shorter duration show similar effect sizes for tiotropium in the prevention of exacerbations. Although the effect-size between the tiotropium and the salmeterol trials cannot be compared directly, the patient populations seem to have COPD of similar severity and the effect size seems to be in the same order of magnitude.

Theophylline, although used widely in the treatment of COPD, is not well documented in its efficacy in reducing COPD exacerbations. Many patients in the trials mentioned above were under constant dose regimens with theophylline preparations, but the contribution of this treatment to the overall treatment effect cannot be derived from existing data.

The mechanisms of action of the effective long-term bronchodilators are different. Therefore, it seems as if long-term bronchodilation in itself might protect from AECOPD.

\section{INHALED GLUCOCORTICOSTEROIDS}

Inhaled corticosteroids (ICS) are potent anti-inflammatory agents and are very effective in this respect against the characteristic inflammation of bronchial asthma. The diseasestabilising and exacerbation-preventing effect in asthma is well documented. However, in COPD with a distinctly different pattern of the chronic ongoing airway inflammation, inhaled steroids have been ineffective in influencing the long-term decline in lung function, which is thought to be a consequence of the chronic inflammatory process, in four large-scale controlled trials [14-17]. On the other hand, several trials have shown systemic prednisone to be an effective treatment for the initial phase of an acute COPD-exacerbation [18, 19]. There seem to be aspects of at least this acute inflammatory response that are responsive to corticosteroids. This led to the analysis of the long-term trials with inhaled corticosteroids in COPD with respect to exacerbation rates. The first of these trials to suggest

TABLE 1 Long-acting $\beta_{2}$-agonists and chronic obstructive pulmonary disease exacerbations

\begin{tabular}{|c|c|c|c|c|c|c|c|}
\hline Author & Year & Treatment & Patients & FEV $1 \%$ pred & Exac. $\cdot$ Patient $\cdot y^{-1}$ & $\Delta \%$ & $p$-value \\
\hline \multirow[t]{2}{*}{ Calverley [8] } & 2003 & Formoterol $9 \mu \mathrm{g}$ b.i.d. & 255 & 36 & 0.91 & -20 & NS \\
\hline & & Placebo & 256 & 36 & $1.14^{\#}$ & & \\
\hline \multirow[t]{2}{*}{ SZAFRANSKI [9] } & 2003 & Formoterol $4.5 \mu \mathrm{g}$ b.i.d. & 201 & 36 & 1.84 & & NS \\
\hline & & Placebo & 205 & 36 & 1.87 & & \\
\hline Calverley [10] & 2003 & Salmeterol $50 \mu \mathrm{g}$ b.i.d. & 372 & 44 & 0.54 & -29 & 0.0003 \\
\hline BRusasco [11] & & Placebo & 400 & 39 & 1.49 & & \\
\hline
\end{tabular}

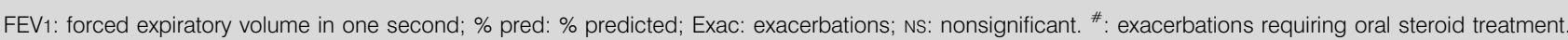

TABLE 2 Tiotropium and exacerbations of chronic obstructive pulmonary disease

\begin{tabular}{|c|c|c|c|c|c|c|c|}
\hline VINCKEN [12] & 2002 & Tiotropium $18 \mu \mathrm{g} \cdot$ day $^{-1}$ & 356 & 42 & 0.73 & -24 & 0.006 \\
\hline \multirow[t]{2}{*}{ Casaburi [13] } & 2002 & Tiotropium $18 \mu \mathrm{g} \cdot$ day $^{-1}$ & 550 & 39 & 0.76 & -20 & 0.045 \\
\hline & & Placebo & 371 & 38 & 0.95 & & \\
\hline Brusasco [11] & 2003 & Tiotropium $18 \mu \mathrm{g} \cdot$ day $^{-1}$ & 402 & 39 & 1.07 & -28 & 0.025 \\
\hline
\end{tabular}

FEV1: forced expiratory volume in one second; \% pred: \% predicted; Exac: exacerbations 
a protective effect of ICS was the Inhaled Steroids in Obstructive Lung Disease (ISOLDE) trial, with fluticasone $2 \times 500 \mathrm{mcg}$ inhaled as metered dose inhaler with a spacer device for 3 yrs [14]. Some further trials with different designs have also directed towards an effect of ICS in protecting against exacerbations of COPD (table 3) [8-10]. This effect seems to be present mainly in those patients with more advanced disease state, as defined by the decline in FEV1.

\section{COMBINATION TREATMENTS}

The most recent attempts in this regard have included trials with the combined preparations of LABA and ICS [8-10]. Here again, there is some indication of a protective effect of this treatment preventing exacerbations (table 4). The effect size in these treatments was slightly, although not significantly better than that for steroids alone. So far there is a paucity of data documenting the effectiveness of the combination of longacting anticholinergics (tiotropium) and inhaled steroids, although in many European countries this combination is used in clinical practice in order to obtain an optimal symptomatic control in advanced COPD. There is also a lack of data on the effectiveness of combined LABA and tiotropium in COPD.

\section{ORAL IMMUNOSTIMULANTS}

Based on a completely different mechanism of action, there have also been trials with OM-85, an oral bacterial lysate treatment, in patients with recurrent exacerbations of chronic bronchitis or mild COPD [20-22]. The mechanism of action of
OM-85 has been discussed in detail elsewhere [23-25]. The stimulation of the gastrointestinal lymphatic system, the upregulation of secretory antibodies and the activation of alveolar macrophages influences the immune and inflammatory responses of the respiratory system. This immunostimulant treatment has been prescribed widely for the prevention of respiratory infections during the winter season in several European countries. There have been only a limited number of randomised controlled trials in adults with chronic bronchitis or COPD so far, which will be discussed in more detail (table 5).

The placebo-controlled study by CoLLET et al. [20] in 381 outpatients with COPD (mean \% predicted FEV1 $42.3 \%$ for OM-85 and $44 \%$ for placebo) studied the exacerbationpreventing effect of OM-85 over 6 months. The risk of having an acute infection or the rate of exacerbations was similar in the two groups. However, the severity of the respiratory exacerbations was influenced by this treatment, with the number of days in hospital for lower respiratory tract infections being 55\% less in the group treated with OM-85, and the risk of needing hospitalisation was reduced by $30 \%$. The reduction in the severity of these infections is an intriguing effect of this oral treatment, which at least from a healtheconomic point of view is interesting in the context of COPD [26, 27].

A similar protective effect of the oral immunostimulant was seen in the trial by ORCEL et al. [21], who investigated 354

TABLE 3 Inhaled corticosteroids and chronic obstructive pulmonary disease exacerbations

\begin{tabular}{|c|c|c|c|c|c|c|c|}
\hline Author & Year & Treatment & Patients & FEV $1 \%$ pred & Exac. $\cdot$ Patient $\cdot y r^{-1}$ & $\Delta \%$ & p-value \\
\hline BURGE [14] & 2000 & Fluticasone $500 \mu \mathrm{g}$ b.i.d. & 373 & 50 & 0.99 & -25 & 0.026 \\
\hline \multirow[t]{2}{*}{ SZAFRANSKI [9] } & 2003 & Budesonide $200 \mu \mathrm{g}$ b.i.d. ${ }^{\#}$ & 198 & 37 & 1.59 & -15 & NS \\
\hline & & Placebo & 205 & 36 & 1.87 & & \\
\hline Calverley [8] & 2003 & Budesonide $200 \mu \mathrm{g}$ b.i.d." & 257 & 36 & 0.87 & -24 & 0.044 \\
\hline Calverley [10] & & Placebo & 361 & 44 & 0.76 & & \\
\hline
\end{tabular}

FEV1: forced expiratory volume in one second; \% pred: \% predicted; Exac: exacerbations; Ns: nonsignificant. ${ }^{*}$ : metered dose; delivered dose=160 $\mu \mathrm{g}$.

TABLE 4 Combination treatment with inhaled corticosteroids and long-acting bronchodilators

\begin{tabular}{|c|c|c|c|c|c|c|c|}
\hline Author & Year & Treatment & Patients & FEV $1 \%$ pred & Exac. Patient $\cdot \mathrm{yr}^{-1}$ & $\Delta \%$ & p-value \\
\hline \multirow[t]{2}{*}{ Calverley [8] } & 2003 & BUD/FOR 320/9 $\mu \mathrm{g}$ b.i.d." & 254 & 36 & 0.63 & -24 & 0.001 \\
\hline & & Placebo & 256 & 36 & $1.14^{\circ}$ & & \\
\hline \multirow[t]{2}{*}{ SZAFRANSKI [9] } & 2003 & BUD/FOR 160/4.5 $\mu \mathrm{g}$ b.i.d. ${ }^{\#}$ & 208 & 36 & 1.42 & -24 & 0.035 \\
\hline & & Placebo & 205 & 36 & 1.87 & & \\
\hline Calverley [10] & 2003 & FLUT/SALM 500/50 $\mu \mathrm{g}$ b.i.d. & 372 & 45 & 0.46 & -39 & 0.0001 \\
\hline
\end{tabular}

FEV1: forced expiratory volume in one second; \% pred: \% predicted; Exac: exacerbations; BUD: budesonide; FOR: formoterol; FLUT: fluticasone; SALM: salmeterol. ${ }^{\#}$ : exacerbations requiring delivered doses; $"$ : exacerbations requiring oral steroid treatment. 
TABLE 5 OM-85 and exacerbations of chronic bronchitis and chronic obstructive pulmonary disease

\begin{tabular}{|c|c|c|c|c|c|c|c|}
\hline Author & Year & Treatment & Patients & FEV $1 \%$ pred & Exac. Patient & $\Delta \%$ & p-value \\
\hline Collet* [20] $^{*}$ & 1997 & OM-85 & 191 & 42 & $0.57(287)$ & 0 & NS \\
\hline \multirow[t]{2}{*}{ ORCEL' [21] } & 1994 & OM-85 & 147 & 55 & 112 LRTIS & -28 & 0.05 \\
\hline & & Placebo & 143 & 55 & 156 LRTIS & & \\
\hline SoLĖk ${ }^{+}$[22] & 2004 & OM-85 & 142 & 85 & 0.61 Exac. pat. & -29 & 0.03 \\
\hline
\end{tabular}

FEV1: forced expiratory volume in one second; \% pred: \% predicted; Exac: exacerbations; LRTI: lower respiratory tract infections; NS: nonsignificant. ${ }^{*}$ : data presented as the number of exacerbations per patient, followed by the number of hospital days due to exacerbations for the whole treatment group; " number of exacerbations for both treatment groups; ${ }^{+}$: number of exacerbations per patient.

elderly subjects with chronic bronchitis, living in institutions for the elderly. Only a subgroup had significant COPD, but all had a history of at least four bronchitis exacerbations in the year before entering the study. They found a $28 \%$ reduction in the number of lower respiratory tract infections and antibiotic prescriptions in the OM- 85 treated group. This effect was entirely due to a reduction in the rate of bronchitis exacerbations, while the number of pneumonias was not different between the groups.

The most recent randomised controlled trial, presented only in abstract form [22], studied the protective effect of OM-85 in outpatients with chronic bronchitis or mild COPD (Global Initiative for Chronic Obstructive lung Disease (GOLD) stages I or II) over 6 months. These patients were selected during an acute bronchitic exacerbation in the autumn and were treated with $\mathrm{OM}$ for 30 days, followed by 10 days per month for months 3,4 and 5. Again, there was a protective effect against further acute exacerbations of chronic bronchitis with a $29 \%$ reduction in the number of exacerbation-events per patient in the active treatment group by the end of the treatment period.

In the setting of chronic bronchitis and mild-to-moderate COPD, therefore, OM-85, given orally for 30 days, followed by 10 days per month in months 3,4 and 5 , seems to protect against bronchitic exacerbations over a period of 6 months. These studies were all conducted over the winter season, while no longer treatment periods with this bacterial lysate have been studied so far. The effect size of this treatment was comparable to that of inhaled steroids or LABA, although the study populations were not directly comparable. The studies available so far with this oral bacterial lysate have been assessed in a recent meta-analysis [28]. When only the three most recent and best quality studies were combined, the number needed to treat to prevent an exacerbation was calculated to be $\sim 15.4(95 \%$ CI $5.5-\infty)$ [28]. Overall, there is still a paucity of studies in patients with a well-defined COPD in advanced GOLD-stages and a lack of studies longer than 6 months.

\section{OUTLOOK}

As the mechanism of action of OM- 85 is distinctly different from that of the inhaled "standard-treatments" for chronic obstructive pulmonary disease, the question comes up, if the combined use of an effective inhaled anti-inflammatory regimen and/or bronchodilator regimen and the immunomodulating oral OM-85 might lead to an additive or even better protection from chronic obstructive pulmonary diseaseexacerbations. To answer this question, more controlled clinical trials with OM-85 in well defined patients with advanced chronic obstructive pulmonary disease are needed, where preventing an exacerbation can be expected to result in the most prominent cost savings and improvements in quality of life.

\section{REFERENCES}

1 Royal College of Physicians. NICE-Guideline on chronic obstructive pulmonary disease. Thorax 2004; 95: Suppl. 1, $1-232$.

2 Kanner RE, Anthonisen NR, Connett JE. Lower respiratory illnesses promote FEV1 decline in current smokers but not in ex-smokers with mild chronic obstructive pulmonary disease: results from the lung health study. Am J Respir Crit Care Med 2001; 164: 358-364.

3 Donaldson GC, Seemungal TA, Bhowmik A, Wedzicha JA. Relationship between exacerbation frequency and lung function decline in chronic obstructive pulmonary disease. Thorax 2002; 57: 847-852.

4 Seemungal TA, Donaldson GC, Paul EA, Bestall JC, Jeffries DJ, Wedzicha JA. Effect of exacerbation on quality of life in patients with chronic obstructive pulmonary disease. Am J Respir Crit Care Med 1998; 157: 1418-1422.

5 Monso E, Ruiz J, Rosell A, et al. Bacterial infection in chronic obstructive pulmonary disease: a study of stable and exacerbated outpatients using the protected specimen brush. Am J Respir Crit Care Med 1995; 152: 1316-1320.

6 Rohde G, Wiethege A, Borg I, et al. Respiratory viruses in exacerbations of chronic obstructive pulmonary disease requiring hospitalisation: a case-control stoudy. Thorax 2003; 58: 37-42.

7 Garcia-Aymerich J, Monso E, Marrades RM, et al. Risk factors for hospitalization for a chronic obstructive pulmonary disease exacerbation - EFRAM-study. Am J Respir Crit Care Med 2001; 164: 1002-1007.

8 Calverley PM, Boonsawat W, Cseke Z, et al. Maintenance therapy with budesonide and formoterol in chronic obstructive pulmonary disease. Eur Respir J 2003; 22: 912-919. 
9 Szafranski W, Cukier A, Ramirez A, et al. Efficacy and safety of budesonide/formoterol in the management of chronic obstructive pulmonary disease. Eur Respir J 2003; 21: 74-81.

10 Calverley P, Pauwels R, Vestbo J, et al. Combined salmeterol and fluticasone in the treatment of chronic obstructive pulmonary disease: a randomized controlled trial. Lancet 2003; 361: 449-456.

11 Brusasco V, Hodder R, Miravitlles $M$, et al. Health outcomes following treatment for six months with once daily tiotropium compared with twice daily salmeterol in patients with COPD. Thorax 2003; 58: 399-404.

12 Vincken W, van Noord JA, Greefhorst APM, et al. Improved health outcomes in patients with COPD during $1 \mathrm{yr}^{\prime}$ 's treatment with tiotropium. Eur Respir J 2002; 19: 209-216.

13 Casaburi R, Mahler DA, Jones PW, et al. A long-term evaluation of once-daily inhaled tiotropium in chronic obstructive pulmonary disease. Eur Respir J 2002; 19: 217-224.

14 Burge PS, Calverley PMA, Jones PW, et al. Randomised, double blind, placebo controlled study of fluticasone propionate in patients with moderate to severe chronic obstructive pulmonary disease: the ISOLDE trial. BMJ, 320: 1297-1303.

15 Pauwels R, Lofdahl CG, Laitinen LA, et al. Long-term treatment with inhaled budesonide in persons with mild chronic obstructive pulmonary disease who continue smoking: European Respiratory Society Study on Chronic Obstructive Pulmonary Disease. N Engl J Med 1999; 340: 1948-1953.

16 Vestbo J, Sorensen $\mathrm{T}$, Lange $\mathrm{P}$, et al. Long-term effect of inhaled budesonide in mild and moderate chronic obstructive pulmonary disease: a randomized controlled trial. Lancet 1999; 353: 1819-1823.

17 Lung Health Study Research Group. Effect of inhaled triamcinolone on the decline in pulmonary function in chronic obstructive pulmonary disease. N Engl J Med 2000; 343: 1902-1909.

18 Niewoehner DE, Erbland ML, Deupree RH, et al. Effect of systemic glucocorticoids on exacerbations of chronic obstructive pulmonary disease. N Engl J Med 1999; 340: 1941-1947.
19 Davies L, Angus RM, Calverley PMA. Oral corticosteroids in patients admitted to hospital with exacerbations of chronic obstructive pulmonary disease: a prospective randomised controlled trial. Lancet 1999; 354: 456-460.

20 Collet JP, Shapiro S, Ernst P, et al. Effects of an immunostimulating agent on acute exacerbations and hospitalizations in patients with chronic obstructive pulmonary disease. Am J Respir Crit Care Med 1997; 156: 1719-1724.

21 Orcel B, Delclaux B, Baud M, Derenne Ph. Oral immunization with bacterial extracts for protection against acute bronchitis in elderly institutionalized patients with chronic bronchitis. Eur Respir J 1994; 7: 446-452.

22 Solèr M, Mütterlein R, Cozma G. Prevention of acute exacerbations in chronic bronchitis and COPD with OM85: a double-blind, placebo-controlled trial. ATS International Conference Proceedings 2004, A766.

23 Lusuardi M, Capelli A, Donner CF. Lung immune defences after stimulation of gut-associated lymphoid tissue with OM-85 BV: a double-blind study in patients with chronic bronchitis. Eur Respir Rev 1996; 6: 182-185.

24 Emmerich B, Emslander HP, Pachmann K, et al. Local immunity in patients with chronic bronchitis and the effects of a bacterial extract, Bronco-AvxomR, on T-lymphocytes, macrophages, gamma-interferon and secretory immunoglobulin A in bronchoalveolar lavage fluid and other variables. Respiration 1990; 57: 90-99.

25 Quezada A, Maggi L, Perez MA, Rodriguez J. Effect of bacterial antigen lysate on IgG and IgA levels in children with recurrent infections and hypogammaglobulinaemia. $J$ Inv Allergol Clin Immunol 1999; 9: 178-182.

26 Grove AK, Bergemann R, Keller R. Preventive treatment of chronic bronchitis: a cost-effectiveness analysis for an immunoactive bacterial extract in Switzerland. BMJ Economics 1996; 10: 1-14.

27 Collet JP, Ducruet T, Haider S, et al. Economic impact of using an immunostimulating agent to prevent severe acute exacerbations in patient with chronic obstructive pulmonary disease. Can Respir J 2001; 8: 27-33.

28 Steurer-Stey C, Bachmann LM, Steurer J, Tramèr MR. Oral purified bacterial extracts in chronic bronchitis and COPD: systematic review. Chest 2004; 126: 1645-1655.

\section{AUTHOR CORRECTION}

“Treatment of stable COPD: antioxidants”. W. MacNee. Eur Respir Rev 2005; 14: 94, $12-22$.

Figure 1. Eur Respir Review 14: 94 p. 13. This figure has been redrawn from Bowler RP, Barnes PJ, and Crapo JD. The role of oxidative stress in chronic obstructive pulmonary disease. COPD: Journal of Chronic Obstructive Pulmonary Disease. 2004; 1: 255277 with permission. Copyright Taylor \& Francis Group, 2005.

Figure 2. Eur Respir Review 14: 94 p. 13. This figure has been redrawn from Bowler RP, Barnes PJ, and Crapo JD. The role of oxidative stress in chronic obstructive pulmonary disease. COPD: Journal of Chronic Obstructive Pulmonary Disease. 2004; 1: 255277 with permission. Copyright Taylor \& Francis Group, 2005. 